\title{
Participación ciudadana en américa del sur: institucionalidad y acciones ciudadanas tras la dictadura en Argentina y Brasil ${ }^{*}$
}

Citizen participation in south america: institutionality and citizen's actions after the dictatorship in Argentina and Brazil

\section{Resumen}

El artículo presenta un estudio de los mecanismos institucionales de participación ciudadana y de las acciones ciudadanas participativas establecidas tras la dictadura en los países de Argentina y Brasil. Mediante un trabajo histórico hermenéutico se resaltan y describen, principalmente, los mecanismos y acciones que se han sostenido en el tiempo, que persisten en la consecución de derechos y que se ocupan de la expansión de fronteras sociales, políticas y económicas.

Palabras clave: Participación ciudadana, mecanismo institucionales, acciones ciudadanas, Argentina, Brasil.

\begin{abstract}
The article presents a study of the institutional mechanisms for citizen participation and participatory citizenship actions established after the dictatorship in the countries of Argentina and Brazil. Through a hermeneutic historical work they are highlighted and described mainly mechanisms and actions that have been sustained over time, which persist in pursuing rights and dealing with the expansion of social, political and economic boundaries.
\end{abstract}

Key words: Citizen participation, institutional mechanism, citizen action, Argentina, Brazil.

\section{Introducción}

La participación ciudadana, entendida como la incidencia de los individuos y los grupos sociales en las diferentes etapas en las que se exponen y resuelven asuntos de interés público (Bolos, 1995), se torna una labor indispensable para el apropiado funcionamiento de los Estados contemporáneos de América del Sur que, por lo demás, sustentan gran parte de su aparato burocrático en la concreción de servicios y programas sociales tendientes a satisfacer las necesidades de sus pobladores. Es importante tener en cuenta que "la administración debe actuar de cara a la sociedad y no quedar solamente en mera administración gubernamental, mientras más públicos sean los actos del Estado será más legítimo" (Guillen, 2009, p. 180).

\footnotetext{
"El presente artículo deriva del trabajo de consultoría "Sistematización de buenas prácticas en participación ciudadana como mecanismo de sostenimiento de servicios y programas sociales en América del Sur", realizado en el año 2014 para el MCDS del Ecuador.
}

Mauricio Chamorro Rosero*

Recepción

23 de marzo de 2016

Revisión:

23 de marzo de 2016

Aprobación:

11 de mayo de 2016 
La profesora Nuria Cunill define la participación ciudadana como "la intervención de la sociedad civil en la esfera de lo público" (1991, p. 49). Igualmente, el término de participación es utilizado para definir "un proceso gradual mediante el cual se integra al ciudadano en forma individual o participando en forma colectiva, en la toma de decisiones, la fiscalización, control y ejecución de las acciones en los asuntos públicos y privados que lo afectan en lo político, económico, social y ambiental para permitirle su pleno desarrollo como ser humano y el de la comunidad en que se desenvuelve" (González, s/f). Lo anterior viabiliza la generación de conciencia crítica y propositiva en el ciudadano.

En este sentido, la participación ciudadana y la formación de una sociedad civil se manifiestan como un elemento central para el fortalecimiento del régimen democrático, en virtud de que permiten el control de la gestión gubernamental, la expresión de demandas y el fortalecimiento del pluralismo requerido por la democracia (Programa de Naciones Unidas para el desarrollo, 2004). Con la participación ciudadana se pretende que la población medie e intervenga en las políticas y decisiones públicas.

Para cumplir con el objetivo es necesario institucionalizar mecanismos, procesos y organismos a través de un acervo legal. Sin embargo, la existencia de una ley adecuada es un paso ineludible pero nunca suficiente para que la mediación e intervención produzcan resultados tangibles en la práctica. Por esa razón es importante estudiar no únicamente las prácticas y los mecanismos institucionales de participación ciudadana, sino, también, adentrarse al estudio de esas acciones que se gestan en la cotidianidad, que son el resultado de la búsqueda -por parte de la sociedad civilde la satisfacción de las necesidades sociales y la inclusión política.

A continuación se presenta un estudio de los mecanismos institucionales de participación ciudadana y de las acciones ciudadanas participativas de dos países de América del Sur que sobrellevaron procesos dictatoriales -y con ello supresión de cualquier forma de participación ciudadana- en la segunda mitad del siglo XX: Argentina y Brasil. Se resaltan los mecanismos y acciones que, tras las dictaduras finalizadas en 1983 y 1985, se han sostenido en el tiempo, que persisten en la consecución de derechos y que se ocupan de la expansión de fronteras sociales, políticas y económicas.

\section{Participación ciudadana en Argen- tina: entre la institucionalidad y la cotidianidad}

Las dictaduras militares acontecidas en Argentina en el transcurso del siglo $X X$, esencialmente la de 1976 a 1983, irrumpieron en cualquier forma participativa que podría gestarse hasta el momento, impidiendo su progresivo desarrollo y generalizando la forma de terrorismo de Estado. El autodenominado "proceso de reorganización nacional" suspendió la actividad política y los derechos de los trabajadores, intervino los sindicatos, prohibió las huelgas, disolvió el congreso y los partidos políticos, censuró los medios de comunicación, se apoderó de numerosos organismos, entre otras múltiples actividades que cooptaban definitivamente cualquier atisbo de participación de la ciudadanía (Rapoport y Spiguel, 2004).

Con la terminación de la dictadura, en el año de 1983 se presentaron vientos de cambio en torno a los roles del Estado y emergieron renovados paradigmas de la administración pública. En ese contexto no dejaron de estar presentes la dimensión jurídica institucional y las importantes herramientas que, a partir de la recuperación democrática, se fueron incorporando al marco legislativo y constitucional de Argentina (Fidyka, 2007). El primero de ellos se presentó en el año de 1985 con la promulgación de la Ley № 23.298, la cual garantiza a los ciudadanos el derecho de asociación política para agruparse 
en partidos políticos democráticos (Hernández y Belisle, 2008). Posteriormente, se presenta la reforma constitucional de 1994 que incorpora de manera taxativa los derechos y mecanismos de participación ciudadana.

Distintos acuerdos e instrumentos internacionales ubican la participación ciudadana entre los ejes centrales que deben perseguir los gobiernos y la administración. Argentina no es ajena a esos propósitos, por esa razón ha desarrollado un marco normativo que permite presuponer que la participación ciudadana se encuentra al alcance de todos. No obstante, los obstáculos son variados y, desde el punto de vista institucional, la participación no alcanza los indicadores deseados.

\section{La participación en la Constitución Nacional y las constituciones provin- ciales}

Entre los aportes normativos más destacados de la Constitución Nacional se encuentra la jerarquización constitucional de instrumentos internacionales de derechos humanos, el derecho de los pueblos indígenas argentinos, el Defensor del Pueblo y el reconocimiento de nuevos derechos y garantías como los derechos de incidencia colectiva en general. Igualmente, mediante el mandato constitucional se otorgó la acreditación de algunos mecanismos de democracia semidirecta, incorporados en el capítulo de Nuevos Derechos y Garantías, como la iniciativa popular (artículo 39 y Ley $\mathrm{N}^{\circ}$ 24.747) y la consulta popular (artículo 40).

Una innovación trascendental en materia de derechos, que incide fuertemente en el marco normativo de la participación ciudadana, lo constituye la jerarquización constitucional de determinados instrumentosinternacionales de derechos humanos ${ }^{1}$. Cada instrumento

\footnotetext{
1 El artículo 75 inciso 22 de la Constitución Nacional de Argentina incorpora en las condiciones de su vigencia la Declaración Americana de los Derechos y Deberes del Hombre, la Declaración Universal de Derechos Humanos, la Convención Americana sobre Derechos Humanos, el Pacto Internacional de Derechos Económicos, Sociales y Culturales, el Pacto Internacional de Derechos Civiles y Políticos y su Protocolo Facultativo, la Convención sobre la Prevención y la Sanción del Delito de Genocidio, la Convención Internacional sobre la Eliminación de todas las
}

internacional, incorporado en rango constitucional, tiene relación con la participación ciudadana. En este sentido, el marco normativo de la participación ciudadana en Argentina debe inferirse desde una óptica nacional e internacional.

Adicionalmente, enlasegundamitaddeladécada de 1990 se acentuó en la República Argentina la tendencia favorable a la construcción de democracias participativas, tanto a través del constitucionalismo provincial como por medio de la reforma de leyes fundamentales provinciales (Arrau, 2004). Así las cosas, las constituciones provinciales incorporaron y ampliaron los mecanismos participativos de la Constitución Nacional y agregaron, desde sus preámbulos, la iniciativa de participación ciudadana como un valor compartido, socialmente reconocido $y$, sobre todo, como un deseo a ser alcanzado y consolidado en el futuro. Algunos mecanismos participativos incorporados en las constituciones son: el referéndum, la revocatoria popular, los consejos participativos, las audiencias públicas, presupuesto participativo, el libre acceso a la información pública gubernamental, entre otros.

En varios artículos de las constituciones provinciales, la participación ciudadana surge como derecho y deber (Chaco, Chubut, Misiones, Río Negro), como forma de gobierno (Formosa, San Juan, Ciudad Autónoma de Buenos Aires) y, entre los fines del Estado, como un gran principio general orientador de las políticas públicas (Chubut, Jujuy, La Rioja, Neuquén, San Luis, Santa Fe, Santiago del Estero, Ciudad Autónoma de Buenos Aires). De ahí que, desde una perspectiva constitucional, el marco normativo de la participación ciudadana en Argentina favorezca la correlación entre la institucionalidad y la sociedad civil.

\section{Las nuevas herramientas institucionales de participación ciudadana tienen dos}

Formas de Discriminación Racial, la Convención sobre la Eliminación de todas las Formas de Discriminación contra la Mujer, la Convención contra la Tortura y otros Tratos o Penas Crueles, Inhumanos o Degradantes y la Convención sobre los Derechos del Niño. 
características principales; por un lado permiten una mayor transparencia y difusión de los actos públicos y, por otro, posibilitan a los ciudadanos involucrarse, en mayor o menor medida (desde lo consultivo a lo participativo), en el diseño, la elaboración y la ejecución de las políticas públicas (Eberhardt, 2008). En este sentido, Argentina ha incorporado de manera sobresaliente los mecanismos participativos en el marco constitucional (tanto en la Constitución de la Nación, como en las constituciones provinciales).

De las veinticinco constituciones que se encuentran enArgentina (incluida la Constitución Nacional), en veintitrés de ellas se reconoce al referéndum como mecanismo de participación ciudadana. Además, la constitución de la ciudad de Buenos Aires ha incorporado la totalidad de los mecanismos de participación ciudadana que existen en Argentina. Sin embargo, contrario a la constitución de la ciudad de Buenos Aires, las constituciones provinciales de Entre Ríos y Santa Fe aún se encuentran en un incipiente desarrollo de los mecanismos de participación institucional.

Un marco jurídico instituido denota interés por el ejercicio participativo y permite reconocer la necesidad de profundizar en el desarrollo de los mecanismos de participación. Sin embargo, la participación no se trata exclusivamente de un problema de producción normativa y de destinación de recursos, ya que también involucra otras circunstancias como la apatía, la falta de compromiso y la carencia de información de la ciudadanía frente a todo lo relacionado con la participación (Eberhardt, 2008).

En el año 2013 una encuesta realizada en la ciudad de Córdoba por la Red Ciudadana Nuestra Córdoba, evidenció que cerca del $75 \%$ de los habitantes de esta región de Argentina se encuentran de acuerdo en que el ejercicio participativo de la democracia se haga a través de organizaciones sociales. Esta cifra contrasta con el $54 \%$ de los habitantes que están de acuerdo en que dicho ejercicio se haga a través de partidos políticos.

Según Martín Tanaka (1998), el colapso del sistema de partidos principia en la incapacidad que tienen estos para sobrellevar las crisis económicas y la violencia política. Además, los partidos políticos crearon una estructura clientelar para favorecer a la burocracia partidista, lo que obstruyó la consolidación de la democracia. Por lo tanto, la legitimidad de los partidos político se ha visto superada por la de las organizaciones sociales.

Es interesante observar que la participación ciudadana en Argentina se encamina al margen de las lógicas institucionales y formales, como son los mecanismos de participación consagrados en las constituciones y las leyes, y se encauza en la búsqueda de la satisfacción de las necesidades y urgencias cotidianas a partir de acciones ciudadanas participativas concretas, como lo demuestra la organización de las Asambleas Barriales, las Asambleas Socio-ambientales y la Unión de Asambleas Ciudadanas.

\section{Las Asambleas Barriales y Las Asambleas Socio-ambientales}

A finales del año 2001 Argentina se encontraba sumergida en una profunda crisis económica, política y social. La implementación del modelo económico neoliberal durante la década de 1990 implicó un fuerte proceso de desindustrialización, concentración de la riqueza y del poder. El aumento en la desigual distribución del ingreso, el incremento de la desocupación, la reducción de los ingresos reales de los sectores de bajos recursos y el aumento de la pobreza e indigencia (Giarracca y Teubal, 2007), ocasionaron la intensificación de la exclusión social, la desarticulación del tejido social, el debilitamiento de las instituciones y la baja intensidad de la participación ciudadana.

En consecuencia, durante la primera década 
del siglo $\mathrm{XXI}$, en los contextos urbanos $\mathrm{y}$ rurales del país, se desarrollaron acciones de protesta llevadas adelante por nuevos actores sociales (pequeños y medianos productores, campesinos, indígenas, trabajadores desocupados, mujeres agropecuarias, etc.) con el propósito de defender y preservar los derechos adquiridos en los procesos democratizadores del siglo XX, que se estaban viendo amenazados (Giarracca y Gras, 2001). "Este ciclo de protestas que se inicia en el interior del país fue confluyendo en un proceso de identificación colectiva que desembocó en los acontecimientos del 19 y 20 de diciembre de 2001 y la conformación del movimiento asambleario" (Hadad et al., 2013, p. 305).

Con estos antecedentes, las jornadas comúnmente denominadas como "el diecinueve y veinte" procuraron la conformación de un importante movimiento asambleario. "Desde los últimos días del año 2001 y durante el mes de enero de 2002 surgieron las asambleas barriales principalmente en la ciudad de Buenos Aires y los primeros cordones del conurbano bonaerense pero también en otros centros urbanos del país" (Hadad et al., 2013, p. 307). De esta forma, comenzando en el barrio los vecinos iniciaron a empoderarse del espacio público a través de debates y discusiones en las plazas y en las calles. Promovieron, además, la tarea de conocer sus necesidades y problemáticas para pensar y concretar soluciones.

En síntesis, como afirma Hadad, Comelli y Petz, las asambleas barriales "recuperaron para la sociedad el sentido de hacer política, redefiniendo esta práctica por fuera de la esfera político-institucional y resaltando la idea de ciudadanía". Igualmente, "constituyeron una instancia de la desprivatización de lo social y reapropiación de lo público no estatal, que se constituyó como la base para recuperar y redefinir la política" (Hadad et al., 2013, p. 309).

Del proceso participativo heredado de las asambleas barriales, aunque con algunas diferencias, surgen las asambleas socioambientales, las cuales son "organizaciones populares que enfrentan día a día la represión y los abusos de parte del poder político y empresarial: no son ONGs ambientalistas, como sostienen confusionistamente desde el poder político. Son asambleas integradas por personas de diferentes extracciones sociales, profesiones y adhesiones políticas" (Espacio Chico Mendes, 2012). Estas asambleas fueron replicadas en los diferentes conflictos socioambientales de Argentina y no queda duda que actualmente son un reconocido sujeto político del campo popular y de la participación ciudadana.

Algunas características de las asambleas socioambientales es que nacen en comunidades alejadas de los grandes centros urbanos. Sus principales objetivos son la lucha en contra de la minería a cielo abierto, en contra de las instalación de pasteras y aquellas otras que se nuclean en contra del monocultivo de soja, establecidas en localidades colindantes con la frontera agraria (Cerutti y Silva, 2011). Es importante mencionar que "las asambleas socioambientales son una forma de organización que busca crear nuevos espacios de participación, heterogéneos, horizontales, sin líderes ni conductores, en los que la ciudadanía puede expresarse y (re)crear otras prácticas políticas" (Hadad et al., 2013, p. 317).

\section{LaUnión deAsambleas Ciudadanas}

En torno a las asambleas socioambientales se ha creado la Unión de Asambleas Ciudadanas (UAC), una instancia nacional de coordinación asamblearia que durante ocho años ha unificado las luchas socioambientales originadas en Argentina. La UAC es un espacio autónomo de encuentro y organización de ciudadanos que enfrentan a las transnacionales y las políticas de recolonización que saquean y destruyen bienes comunes, culturas y pueblos ${ }^{2}$.

La UAC nace el 21 de julio de 2006, como

2 Ver: http://asambleasciudadanas.org.ar/ 
resultado del Foro Nacional de los Pueblos Autoconvocados Ambientalistas, realizado en Córdoba por iniciativa del Grupo 9 de julio Valles del Carmen de Colonia Caroya. Entre los objetivos principales de la UAC se encuentra el de construir identidad y cultura, nuevas subjetividades y espacios autónomos. Desde su nacimiento hasta el presente año, la UAC ha organizado veintidós encuentros ciudadanos. Al reunirse periódicamente, la UAC "ha adquirido una dinámica que integró otras organizaciones territoriales, un importante número de organizaciones no gubernamentales, estudiantiles, referentes políticos de izquierda, intelectuales e investigadores" (Giarracca y Mariotti, 2012, p. 109).

Finalmente, es importante indicar que en Argentina las demandas sociales emergentes, en defensa y protección del medio ambiente, son objeto de amplias campañas -un ejemplo es la UAC- y han conquistado reconocimiento jurídico. En este sentido, se puede asegurar que "las nuevas leyes ambientales son productos de consensos políticos transversales, más que de agendas programáticas" (Delamata, 2013 , p. 65), como se evidencia en la Ley $\mathrm{N}^{\circ}$ 26.331 de 2007 y la Ley $N^{\circ} 26.639$ de 2010, que consagran bienes de carácter público a los servicios ambientales de los bosques nativos y de los glaciares ${ }^{3}$.

\section{Participación ciudadana en Brasil: una lectura desde los mecanismos de gestión y las organizaciones cívicas}

La historia política de Brasil, al igual que la de Argentina, se encuentra marcada por la dictadura y caracterizada por una marginación social de las clases populares. De esta manera, son los avances democráticos en Brasil los que abrieron campo a la posibilidad de hacer efectiva la participación popular y

\footnotetext{
3 Al respecto, Gabriela Delamata asegura que "en algunos de estos procesos de lucha legal son los movimientos campesinos y los pueblos originarios los que adquieren un rol protagónico, como acontece por ejemplo en las resistencias a la deforestación y más concretamente a raíz de la reglamentación provincial de la Ley de Bosques." (2013, p. 58)
}

ciudadana. La participación ciudadana logró surgir e instaurarse con la restauración de la democracia a partir de la carta constitucional de 1988. Actualmente la participación ciudadana en Brasil es determinada como una de las más firmes y activas de todo el cono sur. El país más grande de América del Sur evidencia la lucha de resistencia contra la dictadura, lo que da cuenta de una oposición y una fuerte participación de la sociedad civil al querer reconfigurar su política.

Con las elecciones de 1989 se genera una nueva oportunidad política y social para el país, y se reconstruyen las bases para el debate público, cimentado en los ideales del Partido de los Trabajadores (PT). La creación del PT es una muestra de la participación que se comenzó a instaurar en Brasil. Su formación viene de la asociación sindicalista de operarios sumergidos en el Movimiento Obrero de inicios de la década de 1980, en la cual el partido y demás agentes públicos se interesan por hacer cumplir las órdenes que garanticen los derechos de todos los ciudadanos.

\section{Marco normativo de la participación ciu- dadana en Brasil}

Si bien es importante relacionar las formas de participación ciudadana con el tipo de democracia que manejan en el país, es significativo resaltar el artículo 1 de la carta constitucional de 1988 que establece la soberanía a cada uno de sus ciudadanos, con el fin de ejercer la democracia y la participación pública. Según el parágrafo único de dicho artículo: "Todo el poder emana del pueblo, que lo ejerce por medio de representantes elegidos directamente, en los términos de esta Constitución".

La intervención que tiene el Estado con la instauración de una serie de gestiones institucionales, que incluye la participación de sus habitantes, se reconoce con la singularidad de la llamada Democracia Participativa, un concepto intermediario que agrupa la democracia directa y 
representativa, "por el hecho de ampliar las bases de discusión en la toma de decisiones, a través de la consulta a la sociedad civil, organizada en consejos y/o entidades de representación popular" (Pintaudi, 2005, p. 5). Con todo lo que significa la denominada democracia participativa se inician a redefinir los planes de gobierno y de intervención, pero sobre todo se redefine la agenda pública, lo que promueve una ruptura con el régimen instaurado anteriormente.

La democracia participativa se instaura en Brasil como elemento de conjugación entre la democracia directa y la democracia representativa. En este sentido, el carácter directo de la democracia participativa permite la incidencia de la sociedad civil en la toma de decisiones del Estado, sin necesidad de un intermediario. Por su parte, la representatividad es una variable indispensable en la distribución de labores institucionales, generando una especie de participación indirecta de la sociedad civil.

En este orden de ideas, es posible evidenciar que en Brasil existen varios mecanismos de participación directa, como la libre asociación, la formación de sindicatos, organizaciones comunales y barriales, artística, educativa, deportiva, partidos y movimientos políticos entre un centenar de manifestaciones que generen opinión. Todas ellas viabilizan el influjo de la sociedad civil en los asuntos de carácter públicos $\mathrm{y}$, paralelamente, crean conciencia sobre la importancia de la participación.

Actualmente, en Brasil la acción participativa se rige bajo la Ley Federal No. 10.257 de 10/07/2001, conocida también como Estatuto de la Ciudad, en la cual se establece y se encuentran los distintos mecanismos de participación y, sobre todo, de instrumentos de gestión institucional. Además se determina que la gestión del presupuesto se realice de manera participativa, por medio de debates públicos y consultas populares. A partir de dicha ley federal, la participación ciudadana se viene fortaleciendo a través de consejos que ratifican el poder local, abriendo paso a la participación política y popular de las administraciones municipales.

\section{Presupuesto Participativo}

La constituyente de 1988 propició un nuevo aire político y público para el país. Enfatizado en la descentralización de la política y el bienestar de sus ciudadanos, Brasil inicia su experiencia de participación ciudadana con un modelo propio denominado "Presupuesto Participativo" (Ayala y Hernández, 2014). Aplicado desde 1989, el Presupuesto Participativo procura combatir el clientelismo y lograr una mejor redistribución de los recursos.

Brasil principia su búsqueda de una estabilidad económica con nuevos proyectos comerciales y de mercado, aunque en los años noventa se observaría un aumento en la desigualdad social, pues cerca del $95 \%$ de la población vivía en situaciones desmejoradas, sin un adecuado sistema de bienestar (Pintaudi, 2005). Esto fue uno de los principales desafíos para la política posterior a la de 1990. De esta manera, se inician con énfasis los programas del presupuesto participativo y más adelante comenzarán las campañas de asistencia social.

Varios son los mecanismos institucionales de participación ciudadana instaurados en Brasil con el fin de promover el interés y la intervención en cada uno de los sectores públicos y con el ánimo de generar bienestar. En este sentido, el Presupuesto Participativo, como se mencionaba anteriormente, fue creado para garantizar la preparación y ejecución de programas de redistribución económica o de sus recursos.

La primera etapa de este reconocido sistema se da en Porto Alegre, y desde allí ha sido un modelo aplicable a otras regiones, incluso en otros países, aquella propuesta se basa en tres principios:

- Todos los ciudadanos tienen el derecho de 
participar, siendo que las organizaciones comunitarias no detentan, a este respecto, por lo menos formalmente, status o prerrogativas especiales.

- La participación es dirigida por una combinación de reglas de democracia directa y de democracia representativa, y se realiza a través de instituciones de funcionamiento regular cuyo régimen interno es determinado por los participantes.

- Los recursos de inversión son distribuidos de acuerdo con un método objetivo basado en una combinación de "criterios generales" - criterios sustantivos, establecidos por las instituciones participativas con el objeto de definir prioridades- y de "criterios técnicos"de viabilidad técnica o económica, definidos por el ejecutivo, y normas jurídicas federales, estatales o de la propia ciudad, cuya realización cabe al ejecutivo-. (Santos, 2005, p. 401)

Los principios sobre Presupuesto Participativo hacen una constante invitación a la promulgación de opiniones para profundizar en la cultura de la participación. Sin embargo, existen varias vicisitudes respecto a la participación y la representatividad. La tensión entre los dos tipos de democracias, la participativa y la representativa, presentes en el dictamen de la participación ciudadana, evidencian que la expansión de una de ellas es posible por restricción de la otra.

Sumado a esto, el conflicto efímero donde el Estado divide el poder de establecer criterios para el establecimiento de políticas públicas, tal como lo advierte Silvana Maria Pintaudi (2005), es una de las limitaciones que tiene esta clase de democracia. Además, porque en todo Estado siempre existe la singularidad de quienes participen más que otros, e incluso existe el caso de algunas regiones o ciudades que han perdido el vínculo de la participación después de haber incidido en ello constantemente.
Las virtudes y las contrariedades u obstáculos que posee este tipo de democracias, y en especial programas de participación ciudadana como el de Presupuesto Participativo, su futuro depende de la manera como se perfeccione, actualice y desarrolle propuestas novedosas frente a la inclusión de cuestiones que no han sido tratadas. A pesar de esto, no hay duda que Brasil es uno de los países de América del Sur que más ha desarrollado habilidades para promover la participación ciudadana.

Con todo, es importante resaltar que en 1995 la experiencia de Presupuesto Participativo de Porto Alegre fue elegida entre las 40 mejores intervenciones urbanas, en la Segunda Conferencia Mundial sobre los Asentamientos Humanos (Hábitat II) celebrada en Estambul. Cuatro años después, en 1999, el caso de Porto Alegre fue presentado por el Banco Interamericano de Desarrollo (BID) en el seminario sobre Gestión Social, de Washington D.C. Los reconocimientos otorgados a esta experiencia participativa permitieron que Porto Alegre reciba la primera edición del Foros Social Mundial en enero de 2001.

Desde su implementación en 1989 el número de experiencias de Presupuesto Participativo en Brasil se han incrementado considerablemente. De 13 experiencias en 1992, se pasó a 353 en 2012; en aproximadamente 20 años el Presupuesto Participativo se consolidó como uno de los mecanismos participativos predilectos por la ciudadanía y la institucionalidad. Por lo demás, para el año 2012 la Secretaría Nacional de Articulación Social registraba 300 experiencias de Presupuesto Participativo por fuera de Brasil, distribuidas en 40 países en los 5 continentes.

\section{Sistema Único de Asistencia Social}

La política instaurada en las últimas dos décadas recientes en Brasil, se ha planteado toda forma asociativa para constituir el bienestar de su población. Así, desde la promulgación 
de la Constitución se dio origen al proceso de Asistencia Social, el cual se desarrolla con el fin de suplir las necesidades sociales básicas en el país, aspectos tratados como el tema de la salud pública y educación. Definiendo mejor el concepto de asistencia social tenemos que:

La asistencia social no contributiva se reconoce como un derecho del ciudadano y un deber del Estado brasileño (artículo 206 de la Constitución) y se regula por la Ley Orgánica de Asistencia Social (LOAS) (Brasil 1993). Según esta ley, la asistencia social en Brasil debe promover "los mínimos sociales, realizada a través de un conjunto integrado de acciones de la iniciativa pública y de la sociedad, para garantizar la atención a necesidades básicas" (Brasil 1993, artículo 1).

Sus principios incluyen la supremacía de la atención de las necesidades sobre las exigencias de rentabilidad económica, la universalización de los derechos sociales y el respeto a la dignidad del ciudadano, mientras que sus directrices son la descentralización político-administrativa, la participación de la población por medio de organizaciones representativas en la formulación y control social de las políticas en las acciones de todos los niveles, y la primacía y responsabilidad del Estado en la conducción de la política de asistencia social en cada esfera de gobierno (Brasil 1993, artículos 4 y 5). (Hevia, 2011, p. 98)

En este marco de ideas, la lucha constante del programa busca consolidarse como un derecho fundamental de todos sus ciudadanos, garantizando toda clase de bienestar social. Particularmente en el Gobierno de Lula da Silva, la asistencia social se caracterizó por combatir el trabajo infantil y el abandono estatal a las familias más desfavorecidas, tal como lo enseña el proyecto de transferencia a la renta y Beca-familia.

Cabe anotar que dicha transferencia lograba suplir, aunque de manera mínima, las necesidades elementales de la vida. Utilizada principalmente para pagos de servicios públicos, inversión en la canasta familiar, e incluso -en algunos casos- para el pago de los estudios básicos de los hijos de dichas familias, con el fin de mejorar los estados de vida y comenzar a garantizar las bases de un Estado de bienestar. No obstante, dichos programas se efectúan de manera "focalizada", es decir, se centra en solucionar problemáticas estipuladas 0 específicas, por lo que quedan relegadas otras necesidades que también merecen ser vistas con urgencia.

De igual manera, es importante reconocer que en el año 2004 se aprobó la creación de la Política Nacional de Asistencia Social (PNAS), y un año después se decretó la Norma Operacional Básica del Sistema Único de Asistencia Social (NOB SUAS). Con esto se abrió paso al Sistema Único de Asistencia Social, el cual regula y organiza el PNAS para garantizar el bienestar social, la equidad y la protección a las familias, la descentralización de la política y lo administrativo, el control social y sementar las bases que establezcan una excelente relación entre el Estado y la sociedad civil.

La política de asistencia social, al ser una política de la seguridad social brasilera, debe asegurar protección social, entendida como garantía de derechos y de condiciones dignas de vida (PNAS, 2004).

Para eso debe garantizar, según la PNAS (2004):

1. Renta o Supervivencia, lo que significa garantizar rendimiento para os desprovidos das condições básicas para sua reprodução social em padrão digno e cidadã. [Sic]

2. Seguridad de Acogida, que supone la garantía de las necesidades humanas, que comienza con el derecho a alimentación, a vestimenta, al abrigo, y debe lograr la conquista de la autonomía en la provisión de las necesidades básicas. 
3. Seguridad de poder vivir en la familia o en convivencia, lo que supone estar en contra de las situaciones de reclusión o de pérdida de relaciones sociales. (Mustafa, 2005, p. 3)

La idea de asistencia no contributiva y su calidad de gestión, plantea nuevos mecanismos de participación ciudadana permitiendo mejorar el programa y alejarlo de viejas tradiciones políticas clientelistas. Se puede asegurar que el trabajo de todos los agentes públicos, con los mecanismos de participación, tiene como propósito la consolidación total del programa nacional de asistencia social.

Igualmente, dentro de los programas de asistencia social presentes en los instrumentos de gestión institucional, se encuentran las reconocidas conferencias o Conferencias de la ciudad, significativas en cada proceso de participación para el bienestar y el cumplimiento de los intereses públicos y administrativos. Estas conferencias se efectúan por la convocatoria que hace el Concejo Nacional de Asistencia Social. En ellas se debaten los temas presentes a solucionar, todo respecto a la distribución y la manera equitativa de sostener los servicios básicos en cada región.

Para llevar a cabo las conferencias, en primera instancia, es necesario establecer y convocar una serie de reuniones o conferencias a nivel local o municipal, con el fin de presentar un reporte concienzudo por parte de cada delegado a la etapa final del proceso que es la Conferencia Nacional. Todo se va consolidando alrededor de un año consecutivo, una preparación para presentarse cada dos o cuatro años en la Conferencia Nacional. Todos estos aspectos presentes en Brasil hacen alusión al tipo de democracia deliberativa ampliada hacia la esfera nacional.

Con estos argumentos, podemos establecer que Brasil ha ido ganando paso a paso los espacios de participación ciudadana, siempre dirigido hacia los intereses del bien común. Aunque ese tipo de participación sea propiciado a través de la gestión institucional, proporciona la facultad de la libre opinión, posibilitando la integración social y el desarrollo del país. Aunque son conscientes que falta un largo camino por recorrer para terminar su labor y consolidar de manera óptima las políticas de participación, se preocupan por ampliar sus programas a cada faceta de la esfera pública. Brasil es un modelo en los procesos de participación ciudadana de América del Sur, logra reconfigurar su política, restaurar la democracia y redefinir su agenda pública.

\section{Conclusiones}

En la actualidad es indiscutible la labor de producción normativa que han realizado los países de América del Sur sobre el tema de participación ciudadana. Desde el último cuarto del siglo pasado hasta nuestros días, países como Argentina y Brasil han incorporado los mecanismos de participación ciudadana en sus marcos jurídicos. Además, cabe resaltar el afianzamiento de instituciones y organizaciones que canaliza las finalidades y los deseos del Estado en cuanto a participación.

Desde las Constituciones Nacionales hasta las leyes especiales, mecanismos de participación como el referéndum, los consejos participativos, las audiencias públicas, el presupuesto participativo, el libre acceso a la información pública gubernamental, entre otros, han tomado un lugar prepondérate y ahora ocupan parte inevitable de las agendas públicas de los diferentes gobiernos del continente. En muchos casos la intervención de la sociedad civil en la esfera pública es una realidad, y como resultado se han obtenido grandes réditos en la consolidación de ciudadanía y el fortalecimiento del modelo democrático. No obstante, existen algunos casos donde los gobiernos estatales aún se encuentran en deuda con la instauración institucional de la participación ciudadana, lo que ha dado lugar a la deslegitimación de determinados procesos.

Por otra parte, donde ha sido precaria la incidencia de los individuos y los grupos 
sociales en las diferentes etapas en las que se exponen y resuelven asuntos de interés público, las políticas estatales han excluido los sectores populares y les han negado la voz, han irrumpido en el escenario público los movimientos sociales emprendiendo "la lucha por iguales derechos, justicia [...] y el reconocimiento de un umbral mínimo de derechos asociados con la pertenencia y la inclusión en un sistema social" (Jelin, 1990, p. 206). De ahí la importancia de estudiar en América del Sur la participación ciudadana que se encuentra al margen de los procesos institucionales y que reaparecen en los movimientos sociales. Como asegura Elizabeth Jelin (1990): "esas luchas desde abajo, en sectores sociales subordinados redefinen sus identidades y sus derechos, son una tentativa de ampliar su espacio de acción y extender las fronteras de una ciudadanía social y política".

Finalmente, es importante recordar que la participación ciudadana es un valor democrático en sí mismo, ya que supone una expresión de autonomía, de libertad y de lucha social; los resultados tangibles o logros obtenidos a partir de los procesos de participación no deben medirse por estándares o metas cumplidas, sino por la preocupación e incidencia real de la ciudadanía. En otras palabras, "la participación no es suficiente para eliminar las desigualdades en la sociedad; pero es asimismo cierto que la desigualdad social va unida a la poca o ninguna participación" (Ocles, 2010, p. 97).

\section{Referencias}

Arrau, F. (2004). Participación ciudadana en la gestión pública y su vínculo con las asociaciones: Argentina, España, Estados Unidos y México. Santiago de Chile, Sección Estudios de la Biblioteca del Congreso Nacional de Chile. [impreso]

Ayala, A. y J. Hernández. (2014). "Los presupuestos participativos, una estrategia de dialogo entre ciudadanos y autoridades". En Alfonso Ayala (coord.): Nuevas avenidas de la democracia contemporánea. México, UNAM. [impreso]
Bolos, S. (1995). "Presentación”. En S. Bolos (Coord.). Actores sociales y demandas urbanas. México, Plaza Valdés/UIA. [impreso]

Cerutti, A. y M. Silva. (2011). "Unión de Asambleas Ciudadanas (UAC): Cinco Años de Resistencia y Lucha Socioambiental". Revista Arena Año2 Número 1. Universidad Nacional de Catamarca - Argentina. [link]

Constitución Política de Brasil de 1988. [impreso]

Constitución Nacional de Argentina de 1994. [impreso]

Cunill, N. (1991). Participación Ciudadana. Venezuela, Editorial del CLAD. [impreso]

Delamata, G. (2013). “Actualizando el derecho al ambiente. Movilización social, activismo legal y derecho constitucional al ambiente de 'sustentabilidad fuerte' en el sector extractivista megaminero". Entramado y perspectivas Vol. 3 Número 3. [link]

Eberhardt, L. et al. (2008). Mecanismos de Participación y Control Ciudadano en la Argentina. Buenos Aires. [impreso]

Espacio Chico Mendes (2012). "Reflexiones en torno a la lucha socioambiental en Argentina". Buenos Aires - Argentina. Revista Herramienta $N^{\circ}$ 50. [Disponible en: http://www.herramienta.com.ar/revista-herramienta-n-50/reflexiones-entorno-la-lucha-socioambiental-en-argentina]

Fidyka, L. (2007). Proyecto "Participación Ciudadana: Marco Constitucional de la República Argentina II'. Buenos Aires, Programa Estudios Especiales - Dirección Nacional de Relaciones con la Comunidad - Ministerio del Interior. [link]

Giarracca, N. y M. Teubal. (2007). "La rebelión de 2001." En Daniela Mariotti; María ComeIli; Inés Petz; Juan Wahren; Norma Giarracca y Miguel Teubal. Tiempos de Rebelión: que se vayan todos. Calles y plazas en la Argentina: 2001 y 2002. Buenos Aires, Antropofagia. Pp. 111-134. [impreso] 
Giarracca, N. y C. Gras. (2001). "Conflictos y protestas en la Argentina de finales del siglo $\mathrm{XX}$, con especial referencia a los escenarios regionales y rurales". En Norma Giarracca, (y colab.) La protesta social en la Argentina. Transformaciones económicas y crisis social en el interior del país. Buenos Aires, Alianza Editorial. Pp. 117-142. [impreso]

Giarracca, N. y D. Mariotti. (2012). "Porque juntos somos muchos más'. Los movimientos socioterritoriales de Argentina y sus aliados". OSAL (Buenos Aires: CLACSO) Año XIII, N 32 , noviembre.

González, R. (s/f). Consolidación de la participación ciudadana en Honduras. s/ed, [s.d.]. [impreso]

Guillen, A. et al. (2009). "Origen, espacio y niveles de participación ciudadana". Daena: International Journal of Good Conscience. 4(1). Pp. 179-193. [link]

Hadad, M. et al. (2013). "De las asambleas barriales a las asambleas socioambientales: la construcción de nuevas subjetividades políticas. Argentina 2001-2011", Revista Astrolabio, № 9. [link]

Hernández, A. y J. M. Belisle. (2008). "Regulación jurídica de los partidos políticos en Argentina". En Daniel Zovatto (Coord.): Regulación jurídica de los partidos políticos en América Latina. UNAM. Pp. 191 - 242. [link]

Hevia, F. (2011). "Participación ciudadana institucionalizada y organizaciones civiles en Brasil: articulaciones horizontales y verticales en la política de asistencia social". Revista de Estudios Sociales, Uniandes No 39. Pp. 95 - 108. [link]

Forma de citar: Chamorro Roserro, M. (2016). Participació ciudadanas tras la dictadura en Argentina
Jelin, E. (1990). Women and social change in Latin America. Londres, Zed Books. [impreso]

Mustafa, P. (2005). La política de asistencia social de Brasil en la coyuntura actual: los desafíos de los trabajadores sociales. Ponencia presentada en el XIX Seminario Latinoamericano de Escuelas de Trabajo Social. Universidad Católica Santiago de Guayaquil. Guayaquil, Ecuador. [link]

Ocles, A. (2010). "Participación y socialismo en la Revolución Ciudadana”. En: Miriam Lang y Alejandra Santillana Democracia, Participación y Socialismo. Quito, Fundación Rosa Luxemburg [impreso]

Pintaudi, S. (2005). Participación Ciudadana en la Gestión Pública: Ios desafíos políticos. Revista Electrónica de Geografía y Ciencias Sociales. Universidad de Barcelona. Vol. IX, núm. 194 (102). [link]

PNUD. (2004). La Democracia en América Latina: Hacia una democracia de ciudadanas y ciudadanos. Nueva York, Programa de las Naciones Unidas para el Desarrollo. [impreso]

Rapoport, M. y C. Spiguel. (2004). “Modelos económicos y regímenes políticos y política exterior argentina". En Denis Rolland y José Flávio Sombra Saraiva (Editores): Foreign Politcy and Political Regime. París. [impreso]

Santos, B. (2005). Democratizar la Democracia. Los caminos de la democracia participativa. México, Fondo de Cultura Económica. [link]

Tanaka, M. (1998). Los espejismos de la democracia. Lima, Instituto de Estudios Peruanos. [impreso]

ciudadana en américa del sur: institucionalidad y acciones Brasil. Revista CES Derecho, 7(1), 27-38. 